\title{
Psychologists and Medications in the Era of Interprofessional Care: Collaboration is Less Problematic and Costly Than Prescribing
}

William N. Robiner

University of Minnesota Medical School

Tim R. Tumlin

Tanya Tompkins

Linfield College

Follow this and additional works at: https://digitalcommons.linfield.edu/psycfac_pubs

Part of the Bioethics and Medical Ethics Commons, Pharmacology Commons, Psychiatry and Psychology Commons, Psychoanalysis and Psychotherapy Commons, and the Psychology Commons

\section{DigitalCommons@Linfield Citation}

Robiner, William N.; Tumlin, Tim R.; and Tompkins, Tanya, "Psychologists and Medications in the Era of Interprofessional Care: Collaboration is Less Problematic and Costly Than Prescribing" (2013). Faculty Publications. Accepted Version. Submission 9.

https://digitalcommons.linfield.edu/psycfac_pubs/9

This Accepted Version is protected by copyright and/or related rights. It is brought to you for free via open access, courtesy of DigitalCommons@Linfield, with permission from the rights-holder(s). Your use of this Accepted Version must comply with the Terms of Use for material posted in DigitalCommons@Linfield, or with other stated terms (such as a Creative Commons license) indicated in the record and/or on the work itself. For more information, or if you have questions about permitted uses, please contact digitalcommons@linfield.edu. 
Psychologists and Medications in the Era of Interprofessional Care:

Collaboration is Less Problematic and Costly Than Prescribing

\author{
William N. Robiner \\ University of Minnesota Medical School \\ Tim R. Tumlin \\ Darien, IL \\ Tanya L. Tompkins \\ Linfield College
}

Address correspondence to:

William N. Robiner, Ph.D., A.B.P.P.

Health Psychology

University of Minnesota Medical School

Mayo Mail Code 741

420 Delaware Street, S.E.

Minneapolis, MN 55405

(612) 624-1479 (office)

(612) 624-3189 (fax)

robin005@umn.edu

Key words: interprofessional, integrative care, prescription privileges, prescriptive authority, psychologist, scope of practice 


\begin{abstract}
Increasing emphasis on interprofessionalism and teamwork in healthcare renders psychologists' collaborations critical and invites reexamination of psychologists' roles related to medications. The Collaboration Level outlined by the APA's Ad Hoc Task Force is more achievable and in synch with health reform than prescription privileges (RxP). RxP remains controversial due to training and safety concerns, lacking support from health professionals, psychologists, and consumers. Differences in educational preparation of psychologists relative to prescribing professionals are discussed. Enactment of only three of $170 \mathrm{RxP}$ initiatives reveals RxP to be a costly, ineffectual agenda. Alternatives (e.g., integrated care, collaboration, telehealth) increase access without risks associated with lesser medical knowledge. Concerns about RxP and the movement toward team-based care warrant reconsideration of the profession's objectives regarding psychopharmacology.
\end{abstract}


Psychologists and Medications in the Era of Interprofessional Care: Collaboration is Less Problematic and Costly Than Prescribing

The premise that doctoral-level psychologists should prescribe psychoactive medications to meet mental health needs that are unmet by current prescribers, while theoretically helpful if done well, warrants reassessment as we enter an era emphasizing team-based healthcare. Concerns about the background, breadth and comprehensiveness of training for prescribing that the American Psychological Association (APA) currently advocates to complement psychologists' doctoral training (i.e., most of which is not oriented toward preparing to prescribe) have been raised; many psychologists believing that if psychologists are to prescribe their knowledge and training should be equivalent with that of other prescribers (Baird, 2007). Compromised training for prescribing raises questions about quality and safety that pose both regulatory and public health concerns, and uneasiness for numerous stakeholders. Consideration of whether or not organized psychology should pursue prescriptive authority also should be assessed within the context of existing alternatives-e.g., interdisciplinary care, in which psychologists collaborate with other professionals whose medical training allows more comprehensive management of medications (Butler et al., 2008; Institute of Medicine, Committee on Crossing the Quality Chasm: Adaptation to Mental Health and Addictive Disorder, 2006).

This article begins with a brief review of medications, then explores the roles of collaboration and interprofessional care in the context of increasingly 
compelling healthcare trends that provide psychologists opportunities to contribute substantively to patient care, but that lack the controversy of the agenda promoting prescription privileges for psychologists (RxP). We also review some of the history and concerns about psychologist prescribing, the relative limitations of the APA training model, and the impact of the pursuit of prescription privileges on the field, including the limited success and substantial costs of its legislative record.

\section{Medication Trends}

Medications serve important roles in the arsenal of mental health treatments. According to the Substance Abuse and Mental Health Services Administration (SAMHSA; 2012), use of psychoactive medications increased by $96 \%$ from 127.2 million prescription filled in 1998 to 248.8 million prescription filled in 2007 in the US. In 1998, the market for adult psychoactive medication expenditures was an estimated $\$ 10$ billion. A decade later, psychoactive medication costs were estimated around $\$ 25$ billion (SAMHSA, 2012). During this same period Americans receiving medication-only treatment for mental health problems increased by $13.5 \%$. By contrast, Americans getting combined psychotherapy and medication decreased from $40.0 \%$ to $32.1 \%$, yielding a $13.3 \%$ decrease from $55.9 \%$ to $42.6 \%$ in the percentage engaging in psychotherapy as part of their treatment. These trends exist in the context of emerging evidence of the relative benefits of combined treatments (e.g., Cuijpers, Dekker, Hoon, \& Andersson, 2009). 
The locus of care in which psychopharmacological approaches are used for treating mental health disorders is broad. Up to two-thirds of individuals with mental health and/or substance use disorders are treated by physicians or other healthcare providers in the U.S. (Wang, Lane, Olfson, Pincus, Wells, \& Kessler, 2005) and internationally (Wang et al., 2007). Many additional patients who are seen in primary care settings have sub-clinical mental health issues that may complicate diagnosis/treatment for physical health problems (Kessler et al., 2005). Despite the heterogeneous settings where patients obtain some type of care, nearly $70 \%$ of individuals with mental health conditions have been estimated to receive no treatment for their underlying mental health problems (Kessler et al., 2005). Of the minority who do receive mental health treatment, few are treated with evidence-based approaches that have been shown to be effective (Wang et al., 2002; Wang et al., 2007).

The number of prescriptions written by primary care physicians for psychotropic medications has increased dramatically since the mid 1990s (Lieberman, 2003). Physicians, physician assistants and nurse practitioners, for example, wrote approximately $70 \%$ of all anxiolytic prescriptions, $68 \%$ of all antidepressant prescriptions, $57 \%$ of all prescriptions for stimulants, $43 \%$ of all anti-psychotics, and $28 \%$ of mood stabilizers between August, 2006 and July, 2007 (DuBosar, 2009). Recent data question the efficacy of the most prescribed psychotropic medication, antidepressants, in treating all but severe symptoms (Fournier et al., 2010). There have been calls to re-think medications as a first line form of treatment (Carlat, 2010) and concerns about whether medications 
might be partially responsible for worsening mental health outcomes (Whitaker, 2010) and for inducing various iatrogenic problems (e.g., (Gentile, 2011; Akiskal \& Benazzi, 2006).

Psychologists harbor a range of views of medications and what roles psychologists might best play vis a vis medications (Hayes, Walser, \& Bach, 2002). Whereas most recognize the benefits medications confer for at least some of their patients, many are concerned about potential problems that can be associated with medications, such as adverse effects, risks of abuse, and trends toward overprescribing.

Although shortages of psychiatrists have long been recognized (Pardes \& Pincus, 1983), as public acceptance of psychoactive medications has increased demand for psychopharmaceuticals, the limited access to psychiatrists has gained more attention. Psychologists have been remarkably silent about advocating for increased funding for training psychiatrists, which arguably would be the most direct solution to that problem. Instead, RxP proponents have identified access problems to psychiatrists as a main justification for RxP. Among psychologists, diverse views abound about how to ameliorate the problem of patients facing barriers to providers for psychoactive prescriptions. Advocates of RxP argue that securing prescription privileges provides psychologists direct roles, including the "power to not prescribe, or to help wean patients off medications" (Stambor, 2006, p. 30). On the other hand, RxP opponents contend that collaboration and interprofessional practice are safer and 
more effective approaches by which psychologists can work in conjunction with prescribers to effectively address patients' health and mental health needs.

\section{Collaboration: A Compelling Alternative to RxP}

Whereas specialty mental health services are available from various mental health professionals (psychologists, marriage and family therapist, social workers, psychiatrists, etc.; Robiner, 2006), for individuals experiencing mental health problems general medical settings present critical points of care within the healthcare system. Even patients who recognize their own mental health challenges may be reluctant to seek out specialty mental health care due to various concerns such as finances, insurance coverage, convenience, time, services location, referral inefficiencies, and stigma. This latter concern seems particularly true for ethnic minorities (Snowden \& Pingitore, 2002; Vega, Kolody, Aguilar-Gaxiola, \& Catalano, 1999). Providing mental health services in primary care settings facilitates patients' acceptance of referrals for service, provides greater convenience of co-located services, builds on the already established trust with primary care providers, and increasingly takes advantage of the proximity of multiple types of providers working as a team (Frank, Bray, McDaniel, \& Heldring, 2003).

Primary care settings are important loci of mental health care delivery in that there are a far greater number of physicians and "mid-level providers" (i.e., nurse practitioners and physician assistants) than other mental health prescribers (i.e., psychiatrists, prescribing psychologists) who provide basic mental health services. Nationally, there are an estimated 83,600 physician assistants (Bureau 
of Labor Statistics, 2010) and 105,700 nurse practitioners (Bureau of Labor Statistics, 2012), who by virtue of their sheer numbers are likely to have a far greater impact on meeting medication needs of populations than the relatively small number of psychologists seeking to prescribe could.

Primary care providers are more widely distributed than mental health professionals, who tend to cluster in urban and suburban areas, and consequently are more likely to treat patients in rural areas (Xierali, Tong, Petterson, Puffer, Phillips, \& Blazemore, 2013). Thus, integrated care models that incorporate professionals who are skilled to coordinate a range of treatments, including psychological services, along with medical care by primary care providers, are promising avenues to improve mental health care access and outcomes (Butler et al., 2008).

Under the Patient Protection and Affordable Care Act (PPACA) and the Wellstone-Domenici Mental Health Parity and Addiction Equity Act (MHPAEA), more Americans will have insurance with mental health benefits covered commensurately with general medical benefits. The PPACA has many features intended to enhance and expand healthcare, including promotion of interprofessional care. Consequently, interest in interprofessional collaborative care has been burgeoning. Recently, several organizations have drafted guidelines to support curricula to help prepare future health and mental healthcare providers to engage in interprofessional collaboration (e.g., Institute of Medicine, 2013). The World Health Organization (WHO; 2010) defines collaborative practice in healthcare as occurring "when multiple health workers 
from different professional backgrounds provide comprehensive services by working with patients, their families, ....and communities to deliver the highest quality of care across settings" (p. 13). Moreover, "A collaborative practice-ready health worker is someone who has learned how to work in an interprofessional team and is competent to do so (p.7)".

The WHO considers interprofessional collaborations to be one of the most encouraging solutions regarding healthcare access and distribution problems and complex health-related challenges (HRSA, 2010; APA, 2013; WHO, 2010). Indeed, a shift is underway promoting interprofessional care in healthcare teams and the competencies clinicians need to provide team-based care (Interprofessional Education Collaborative Expert Panel, 2011). Models for providing integrated care (Heath, Wise, \& Reynolds, 2013, March) and for preparing psychologists to function in integrated teams are emerging (e.g., Cubic, Mance, Turgesen, \& Lamanna, 2012).

The Health Service Psychology Education collaborative supported by the APA (2013) Blueprint for Health Service Psychology Education and Training delineated diverse competencies for health service psychology. These include: the "interpersonal skills and communication ...to relate effectively with professionals from other disciplines and demonstrate competence in interprofessional collaborative practice" (p. 29) as well as the consultation competence to "provide consultative psychological services to patients and their families, other health care professionals, and systems related to health and 
behavior" (p. 31) ... and that they "are familiar with evidence-based consulting skills and methods..." (p. 31)

Such developments arguably render the pursuit of RxP less compelling. Noncontroversial measures are gaining ascendance, such as integrating psychologists in diverse healthcare settings, including primary care (American College of Neuropsychopharmacology, 2000; Bluestein \& Cubic, 2009; Tovian, 2006; Frank et al., 2003). Deploying psychologists in primary care settings where they can provide interdisciplinary care in concert with prescribing health professionals (e.g., physicians, advanced practice nurses, physician assistants, consulting psychiatrists) who can manage medications in the context of patients' other healthcare, is not only less costly (Blount et al., 2007; Chomienne et al., 2011), but also obviates the risks of enabling prescriptive authority based on a training model considered controversial by various health professionals, including some psychologists, as will be discussed later in this article.

\section{Collaboration and Psychopharmacology Training}

Increasing psychologists' education related to clinical psychopharmacology is generally accepted as having beneficial effects in enhancing how psychologists engage patients in regard to medications (Smyer et al., 1993). However, enhancing psychologists' understanding about psychoactive medications has never necessitated pressing for RxP (Smyer et al., 1993). When the APA Ad Hoc Task Force on Psychopharmacology (Smyer et al., 1993) reviewed the desirability and feasibility of psychopharmacology prescription privileges for psychologists, it considered three potential levels of training for psychologists to 
consider. Level-2: Training for Collaborative Practice (a consultation-liaison model) was outlined by the APA Task Force (Smyer et al., 1993) but has been largely overlooked in favor of Level 3 training that provides a model for training psychologists to prescribe. Training for collaborative practice would enhance psychologists' knowledge of psychopharmacology to work cooperatively with other health professionals without taking the controversial step of seeking independent prescribing. The collaborative level of training was more strongly favored by psychology graduate students $(77 \%)$ as an option for their own training than prescribing (50\%; Tatman et al., 1997). The Task Force recognized that few psychologists would seek to prescribe (Smyer et al., 1993). Nevertheless, it seems curious that APA developed an agenda seemingly exclusively promoting RxP while consistently ignoring the collaboration model (i.e., we are not aware of guidelines developed for collaboration related to prescribing by other disciplines or efforts to promote the collaboration model).

Disregarding the APA Task Force's Collaborative Practice level seems particularly regrettable in that the APA (2007) Guidelines and Principles for Accreditation of Programs in Professional Psychology already mandate education and training that prepares psychologists to effectively consult with other health and mental healthcare providers so that graduates of all accredited programs presumably have basic skills in consultation, an important ingredient for successful collaboration.

Moreover, collaboration is much closer to what most psychologists actually do. According to the APA Center for Workforce Studies (APA CWS, 2009) Survey of 
Psychology Health Service Providers the vast majority of psychologists collaborate with psychiatrists (89\%), primary care physicians $(79 \%)$, other medical specialists (50\%), nurse practitioners $(51 \%)$, and over a quarter consult collaborate with physician assistants (27\%). Moreover, about $90 \%$ of psychologists regularly discuss medications with physicians and the majority provide information about medications to patients (APA CWS, 2009; Table 4a), an activity that enhances patient care, but does not hinge on psychologists prescribing. These practice patterns of psychologists, in conjunction with the growing momentum of interprofessional team-based care, suggest that it is timely to take another, more serious look at Level-2 training outlined in the APA Task Force report (Smyer et al., 1993) as a potential means of achieving greater consensus in how the profession could most effectively establish collaborative roles for psychologists that capitalize on their on their clinical strengths. Our view on this is not unique. The Canadian Psychological Association (CPA, 2010) Task Force on Prescriptive Authority for Psychologists recently recommended that active collaborative practice with prescribing professions was, "the optimal standard for contemporary psychological practices" (p. 27) rather than promoting RxP.

Psychologists' contributions to collaborative care leverages their expertise and recognized competencies in psychological assessment, intervention, and consultation, and also present opportunities to undertake research that can enhance healthcare. Psychologists who wish to prescribe with training equivalent to other prescribers have always been free to explore more complete 
biomedical training available in other health professions (e.g., physicians, advanced practice nurses, physician assistants). If they wish to be recognized as providing pharmacologic interventions that would indisputably be considered on par with other types of prescribing professionals, it is recommended that their education and training be equivalent to it, beginning with obtaining the undergraduate scientific training and ending with more intensive and broader clinical medical supervised experiences. For example, the Doctor of Nursing Practice degree, which is replacing the master's level nurse practitioner degree, requires a minimum of 1000 supervised clinical hours.

Consumers, employers, and healthcare organizations, such as the Institute of Medicine (2006), are increasingly concerned with promoting quality care and preventing avoidable medical errors. In the current climate of increasing accountability within healthcare it is imperative that providers be sufficiently trained to provide services that meet industry standards and that professionals practice within the contours of their competence.

\section{Psychopharmacology Demonstration Project (PDP)}

Two decades ago the Department of Defense (DoD) undertook a pilot Psychopharmacology Demonstration Project (PDP) training 10 military psychologists to prescribe in a 2-year full time program. When it was cancelled, the Government Accounting Office (GAO) report Need For More Prescribing Psychologists Is Not Adequately Justified concluded that, "training psychologists to prescribe medication is not adequately justified because the [Military Health Services System] MHSS has no demonstrated need for them, the cost is 
substantial, and the benefits are uncertain." (p. 3). NBC news later presented its Golden Fleece award to the project because of its poor cost effectiveness (California Psychiatric Association, n.d.).

The final report of the Evaluation Panel of the PDP considered that,

“... a 2-year program-one year didactic, one year clinical practicum that includes at least a 6-month inpatient rotation-can transform licensed clinical psychologists into prescribing psychologists who can function effectively and safely in the military setting to expand the delivery of mental health treatment to a variety of patients and clients."

It also deemed the psychologist PDP graduates to be weaker medically than psychiatrists (American College of Neuropsychopharmacology, 2000). Rather than being assessed at the level of physicians, the PDP psychologists' medical knowledge was assessed at a student level, which does not allow independent prescribing in any discipline in any jurisdiction. PDP graduates, themselves, recommended against short cuts and reductions in required training. Most said an intensive full-time year of clinical experience, involving inpatients, was indispensible in addition to the comprehensive didactics. These features were not, however, included in the APA training model that was originally developed nor are they in the more recent iteration (APA, 2009). Similarly, they are not systematically incorporated in contemporary clinical psychopharmacology training programs.

\section{APA Training Model and Current Training}


In 1996 the American Psychological Association (APA) adopted the prescription privileges $(\mathrm{RxP})$ agenda as a matter of policy, justifying it partly on the basis of the PDP. It seeks to enable psychologists to prescribe independently, which is not currently the case in most jurisdictions for mid-level non-physician prescribers. APA also endorsed a psychopharmacology training model that was shorter, less intensive, and less organized than the PDP. Eligibility for undertaking the training to prescribe merely requires psychologists graduate from an accredited doctoral psychology program, be licensed, and practice as a "health services provider" psychologist (APA, 2009). Programs are required to have 400 contact hours covering eight domains and an unspecified length, breadth, or intensity of clinical supervised experience (APA, 2009). The APA recommendations for education and training for prescribing is available online (APA, 2009).

Several post-doctoral master's-level psychopharmacology training programs have opened, although none are associated with medical schools. Some are highly reliant on distance learning. RxP programs are designed for psychologists to continue to practice during the training. In contrast to the PDP, contemporary training for psychologists to prescribe is part-time and requires no inpatient training. For example, the Alliant International University (2012) program advertises on its website, "Earn your degree at home on weekends." New Mexico State University (2011) acknowledges on its' website that this truncated schedule may shape course coverage of material: "We will cover as many drug classes as we can in the time allotted." 
Strikingly, the programs do not meet the APA's (2007) own accreditation criteria that are in effect for psychology graduate, internship, and postdoctoral training. That is, they are not required to be carefully scrutinized externally as are other levels of clinical training in psychology and as are other prescribing disciplines' training programs. Even APA's (2009) revised psychopharmacology training model describes training that is narrower and less rigorous than the PDP training.

Although RxP proponents have acknowledged that the PDP training was more consistent with core medical training models in terms of didactics focused on biochemistry, pathophysiology, and clinical medicine than current clinical psychopharmacology training programs (McGrath, 2010), they typically dismiss the relevance of this training and contend that supplementary hours in postdoctoral training in psychopharmacology address these deficiencies in training. The absence of rigorous testing of psychologists' foundational biomedical and scientific deficits precludes understanding their effects. We question how sufficiently foundational deficiencies can be overcome and the advanced knowledge and clinical experience for prescribing can be gained in relatively abbreviated and distance learning training programs. We remain skeptical of the proposition that psychologists might be able to master more quickly the complex nexus of knowledge and skills for prescribing and managing medications than learners in other disciplines.

Some might argue that the relatively cursory training for RxP currently available is a form of "bait and switch" from the more robust PDP training that 
was used to justify RxP originally. The relatively more condensed nature of existing training seems likely to render it inferior to that provided in the PDP as well as relative to the training of other prescribers. It also raises questions about the breadth, depth, and quality of such training. For example, how can consumers and policy makers be assured what other prescribers learn in longer time frames, but that is excluded from an abbreviated curriculum, is not important in maximizing clinical outcomes? After all, when medications enter the human body, they do not just affect emotional regulation within the brain, but have broader physical effects across organ systems (Stuart \& Heiby, 2007) that may interact with other classes of medication.

\section{Differences Between Psychology and (Other) Prescribing Disciplines}

Graduate training in psychology differs substantively from other health professions from the start. It requires neither undergraduate prerequisites nor graduate coursework in basic scientific and biomedical domains (e.g., biology, chemistry, organic chemistry, biochemistry, physiology, pathophysiology, etc.). Such courses are generally recognized as foundational to understanding biological and biochemical processes inherent in health and illness, how the human body responds to medications, and how interactions among systems and medications affect people (Heiby, 2010).

RxP proponents concede that among non-physician health professionals, "...psychology has the core curriculum with probably the least overlap with traditional medical curricula" (Fox, DeLeon, Newman, Sammons, Dunivin, \& Baker, 2009, p. 258). The training paradigms are so different that only $7 \%$ of 
psychology graduate students are estimated (Tatman, Peters, Greene \& Bongar, 1997) to have completed biology and chemistry undergraduate coursework considered adequate for prescribing by APA's own ad hoc Task Force of experts when considering possible levels of psychopharmacology training (Smyer et al., 1993).

In contrast to other health professions, to gain admittance to current RxP training programs, students are neither required to complete scientific foundational course work before enrolling nor to demonstrate competence in those domains through standardized admissions examinations (e.g., MCAT). The Psychopharmacology Examination for Psychologists (PEP), a 150-item, multiple choice test that is the only required testing for psychologists to prescribe contrasts with the more comprehensive, sequential testing such as the United States Medical Licensing Examinations (USMLE Step 1, 2 [CK and CS] and 3). Without more extensive objective testing following rigorous coursework, it is highly speculative to presume that the training psychologists receive could be equivalent to that of physicians or other prescribers, or be sufficient for managing medications, especially in people with complex comorbid conditions, such as older adults. Without broader and in depth physical science education, biomedical knowledge, and experiential medical training, psychologist prescribing arguably constitutes an experiment for which there has been no objective, systematic, or comprehensive evaluation.

Proponents of RxP summarily dismiss the importance of training that aligns with a medical school model requiring students to have a strong foundation in the 
physical sciences (McGrath, 2010). This contention contrasts with the view of many $(78.6 \%)$ psychologists, who believe that to prescribe psychologists should have equivalent training (Baird, 2010). RxP proponents argue that because nonphysician prescribers (e.g., nurse practitioners) provide quality care that results in health outcomes similar to that provided by physicians (e.g., comparable control of asthma, diabetes and hypertension; health services utilization; patient satisfaction; Mundinger et al., 2000) even though they did not attend medical school, psychologists' training need not be equivalent to physicians either. However, as noted by Heiby (2010), all other non-physician prescribers typically do have more extensive scientific (i.e., physical sciences) training at the undergraduate level than psychologists (see Figure 1). Moreover, other prescribers and non-prescribing disciplines have broader and more intensive clinical medical training at the graduate level than is afforded by clinical psychopharmacology training for psychologists.

The absence of scientific and medical training for psychologists in the undergraduate and graduate education sequence leads to questions about how abbreviated training after the education to become a psychologist could be adequate to enable prescribing at levels of knowledge and competence commensurate with other prescribers (see Table 1; Robiner et al., 2002; 2003). The absence of any undergraduate premedical scientific prerequisites to enter training to prescribe violates recommendations of APA's own experts on the APA (1992) Ad Hoc Task Force on Psychopharmacology who stipulated that: 
“...retraining of practicing psychologists for prescription

privileges would need to carefully consider selection criteria, focusing on those psychologists with the necessary science background...It would require students to have undergraduate science training similar to that required of other health service providers (e.g., nurses, pharmacists, allied health professionals, dentists, and/or physicians). It would also require a postdoctoral period of supervised clinical experience." (p. 400).

The potential for insufficient medical preparation is compounded by the reality that many psychologists train in settings outside of the health care system (e.g., schools, counseling centers, prisons, social service agencies). For the APA to unilaterally determine that the basic scientific foundation required in other prescribing professions is unnecessary for psychologists suggests an underestimation of the complexity of the human body and drugs' effects on it. It also could signify inadequate respect of the contributions of those scientific disciplines to the understanding of the mechanisms and effects of medications whose elements are omitted. This calculation to ignore scientific foundations assumedly derives from an objective to provide brief, affordable training so that more practicing psychologists might complete it. Yet, even with this short cut relatively small numbers of psychologists currently prescribe. Concerns about the abbreviated nature of the training fuels opposition to $\mathrm{RxP}$, in various other health professions as well as among psychologists. 
Whereas the interests and competencies of psychologists and psychiatrists overlap, there are differences in training and experience. As Steven Kingsbury, M.D., Ph.D., a psychologist who later became a psychiatrist observed: "Studying the effects of medications on the kidney, the heart, and so forth is important for the use of many medications. Managing these effects is often crucial and has more to do with biochemistry and physiology than with psychology. I was surprised to discover how little about medication use has to do with psychological principles and how much of it is just medical." (Kingsbury, 1992, p. 5).

He also contrasted the intensity and exposure to patients in his training in the two professions:

"In my first month of residency training in psychiatry at a psychiatry emergency service I believe I saw more patients individually than in my entire graduate training [i.e., in psychology]" (Kingsbury, 1987, p. 155)

Although anecdotal, these concerns and differences are not trivial. They are likely representative of the gaps between the medical preparation of psychologists and that of other prescribers.

\section{Psychologists' Perspectives on Psychologist Prescribing}

The RxP movement developed within psychology as some psychologists sought to expand their scope of practice and, thereby, their clinical and economic opportunities. It did not develop in response to entreaties from other health 
professions, public health officials, or consumers, and was not supported by academic psychologists (Lavoie \& Barone, 2006). Although many psychologists support $\mathrm{RxP}$ in principle, unlike other professions with prescriptive authority, $\mathrm{RxP}$ remains controversial among psychologists, particularly when details of legislative proposals are considered (e.g., Hayes \& Heiby, 1998; Heiby, 2002a, 2010; Robiner et al., 2002, 2003; Wagner, 2002, Walters, 2001).

Within psychology, opposing groups have included: the Society for a Science of Clinical Psychology (2001); American Association of Applied and Preventive Psychology (1998); Committee Against Medicalizing Psychology (CAMP; Pollitt, 2003); and most recently, Psychologists Opposed to Prescription Privileges for Psychologists (POPPP; see www.poppp.org).

In contrast to prescribing professions, most psychologists do not intend to prescribe (Baird, 2007; Campbell, Kearns, \& Patchin, 2006), a trend that prevents RxP from becoming a viable strategy for counteracting the shortage of psychiatrists for which it is often touted as a remedy. Even RxP advocates acknowledge that, "...only a minority of practitioners has evinced interest in seeking the ability to prescribe" (Fox et al., 2009, p. 257).

Some psychologists seem to support RxP in theory, although practically speaking express no desire to pursue training or practice; others oppose it (Walters, 2001). Interestingly, psychologists' understanding of the details of prescribing training issues may be limited, so it is difficult to determine what individual psychologists think they support if they do endorse the RxP agenda. Baird's (2007) survey revealed that most $(78.6 \%)$ psychologists believed that to 
prescribe psychologists should receive training commensurate with other nonphysician prescribers. As noted above, APA's current training model does not meet that objective in terms of foundational knowledge, intensity, or breadth of clinical experience, nor oversight through national accreditation.

\section{Professionals' and Consumers' Views of Psychologist Prescribing}

Although, there is consensus on the need for mental health services in the military, and more broadly throughout society, it is unclear whether training psychologists to prescribe is an effective means of addressing these needs. Instead, societal needs might be better served investing resources toward ensuring all mental health consumers have improved access to psychological services, especially evidence-based therapies, which are typically first-line treatments for a host of common mental health issues. For example, after reviewing the published literature on antidepressants and other therapies, the National Health Service in England adopted cognitive behavioral therapy as a first-line treatment for mild and moderate depression and has invested $£ 400$ million over the next four years to increase patient access to psychotherapy to treat depression and anxiety disorders, including plans to train up to 6,000 therapists in cognitive behavioral therapy (Center for Mental Health, 2012).

The RxP agenda is opposed by other health professionals and it undermines interprofessional relations (Bush, 2002). The American Psychiatric Association and the American Medical Association have consistently lobbied against it although conceding they would have no quarrel with psychologists obtaining prescriptive authority as mid-level medical practitioners if their training was 
equivalent to other mid-level practitioners (i.e., nurse practitioners, physician assistants). Opposition to RxP notably extends far beyond organized medicine. The International Society of Psychiatric-Mental Health Nurses (2001) contends that nurses have an "ethical responsibility" to oppose RxP.

Moreover, consumers are wary of RxP. The National Alliance on Mental Illness (NAMI), the largest mental health advocacy and support organization, does not support RxP. NAMl's Executive Director noted that because, "these [psychoactive agents] are serious drugs with serious side effects..."we feel strongly that [prescribing] should be handled by someone with medical training" (Andrews, 2011).

Although RxP advocates claim that psychologists prescribe without problems, there is little, if any, systematic, empirical evidence for the desirability, feasibility, safety, and cost effectiveness of RxP (Lavoie \& Barone, 2006). The unknown consequences of relative deficits in knowledge, experience, and competence associated with abbreviated training raise cautions (American College of Neuropsychopharmacology, 2000; Butler et al., 2008; Robiner et al., 2003). As a public health issue, the fundamental concerns about RxP are patient safety and the quality of care that psychologists could deliver in prescribing relative to other prescribing professions. Gaps in psychologists' training to manage medications, relative to that of other prescribers, presumably persist, even after a psychologist might complete training conforming to the APA model.

Potential Adverse Effects and Limitations of Psychoactive Medications 
Psychoactive medications are commonly used in the treatment of anxiety, depression, insomnia, psychosis, and other conditions, and have become more accepted by consumers. Nevertheless, they are powerful drugs with risks for significant adverse effects that require monitoring by qualified health professionals who can assess their effects. This includes being prepared to discern whether symptoms are due to the prescribed medications, to other medications, to interactions between psychoactive medications and other medications, or whether they might indicate other medical conditions for which treatment is needed; not conditions for who which psychologists are trained to assess or treat.

The potential for harm from psychoactive medications is considerable. The $U$. S. Food and Drug Administration (FDA) requires black box warnings about risks of using antipsychotics with the elderly due to increased risk of death and other adverse effects (cardiac toxicity, stroke, infection, hyperglycemia) and for antidepressants in adolescents and young adults due to possible increased risk of suicidal ideation. SSRIs can cause hematological disorders, including GI and retinal hemorrhage and other serious problems. One study found the odds of mortality were 3.22 times higher for those using anxiolytic and hypnotic medications in the past month (Belleville, 2010). A study of reports to the FDA from 1998 to 2005 revealed 3 -fold increases in serious morbidity and mortality associated with adverse drug events (ADEs), with disproportionate incidence in the elderly (Moore, Cohen, \& Furberg, 2007). Two antidepressants, paroxetine and venlafaxine, were among the agents with the most frequent, serious 
outcomes. Antipsychotics (clozapine, risperidone, olanzapaine) and paroxetine were among drugs with most frequently suspected associated deaths.

Complications associated with psychoactive medications include cardiac arrhythmias, insulin resistance, obesity, movement disorders, neuroleptic malignant syndrome, serotonin syndrome, sexual dysfunctions, and adverse drug event due to drug interactions (Stuart \& Heiby, 2007). Antidepressants and mood stabilizers account for an estimated 20,000 ADEs requiring treatment in emergency departments (EDs; Budnitz, Pollock, Weidenbach, Mendelsohn, Schroeder, \& Annest, 2006). Antipsychotics and benzodiazepines, respectively, accounted for 13,635 and 9,299 ADEs resulting in ED visits. The medical risks and adverse effects associated with these agents, and the costs incurred with care to address them, warrant that prescribers have full understanding of human pathophysiology, morbidity, pharmacology, and the formulary beyond psychopharmacology (Stuart \& Heiby, 2007). Unfortunately, the truncated focus of psychopharmacology training programs for psychologists raises questions about whether the curriculum is sufficiently broad and intensive to address patients' overall functioning.

The rationale for RxP also is questioned as evidence mounts that antidepressants are used to treat mild to moderate conditions for which they may perform no better than placebo (Fournier et al., 2010), potentially resulting in overmedication. It is unclear how knowledgeable and discerning potential prescribing psychologists are about both the adverse effects and the bounds of therapeutic effects. Research suggests that some claims made to clinicians and 
the public through medical journals and direct-to-consumer advertisement may be misleading, lack sufficient empirical support (i.e., well controlled and executed studies) and government oversight (Spielmans, Thiegles, Dent, \& Greenberg, 2008), making it essential that prescribers be sufficiently educated to understand for themselves the science underlying drugs' action.

\section{Controversial Issues Associated With RxP}

Despite such concerns, the APA Practice Organization (APAPO) and its affiliates have mounted campaigns lobbying state legislatures to authorize RxP to psychologists who obtain postgraduate training based on the APA model. Proponents contend that allowing psychologists to prescribe would expand patient access to medications. They posit that expanding psychologists' scope of practice could enhance services for the underserved, such as in rural areas. Whereas access problems do exist and warrant remedy, claims about how well RxP would solve those problems deserve closer scrutiny and have been disputed (Lavoie \& Barone, 2006; Politt, 2003; Robiner et al., 2002).

For example, an article in the American Journal of Law \& Medicine argues that RxP advocates disingenuously mislead legislatures to grant psychologists prescriptive authority (Pollitt, 2003). The reality is that psychologists and psychiatrists have similar demographic distribution patterns, tending to practice in urban and suburban areas, rather than rural areas (see Figure 2). Consequently, $\mathrm{RxP}$ is not likely to meaningfully attenuate rural prescriber workforce shortages. As noted earlier, developing interprofessional collaborations with PCPs is more likely to improve access to psychopharmological services. 
Furthermore, mental health access issues in obtaining psychotherapeutic interventions and psychological assessments in both rural and urban areas may be more challenging than accessing pharmacotherapy (Campbell et al., 2006; Westra, Eastwood, Bouffard, \& Gerritsen, 2006). One study revealed that most family practitioners thought there were psychological and psychiatric services available in their communities for collaboration and consultation, and that they would be reluctant to refer patients to psychologists for pharmacological management (Bell, Digman, \& McKenna, 1995). Other approaches, such as telepsychiatry, offer the potential to compensate for some psychiatric workforce shortages (O'Reilly et al., 2007). The shortage of psychiatrists neither logically nor prudently leads to the conclusion that psychologists should prescribe. As members of the "de facto" mental health system, primary care physicians and mid-level providers can prescribe sufficiently well to meet many patients' needs. Enhancing the systems and intensifying the training that underlie primary care providers' mental health care delivery has the potential to further improve their prescribing quality as does enhancing psychologists' capacity to function effectively in healthcare teams to coordinate care that is based on the interplay of the respective clinical strengths of their disciplines.

\section{The RxP Legislative Record}

APA has allocated considerable resources to promoting RxP. By 2001, APA had spent more than $\$ 1$ million on the RxP legislative agenda (DeLeon, 2002). The APAPO has provided grants to state psychological associations to support RxP lobbying. The full amount that has been spent by the APA and groups of 
RxP supporters is unknown. The authors' requests to the APAPO for financial records related to RxP went unanswered. Conversely, the costs to counter legislative initiatives for RxP is not known. Were RxP not a battleground, such lobbying efforts alternatively could be used collaboratively to promote a broader consensual agenda to advance mental health care and education within and across disciplines.

The campaign to promote RxP has yielded modest success, which in behavioral terms might be characterized as intermittent reinforcement, suggesting that the RxP agenda is not likely to extinguish readily. Guam was the first jurisdiction to pass RxP legislation in 1998. Whereas RxP proponents hail this as an historic milestone in their movement, and widely cite it to justify promoting legislation in other areas, it seems misleading in that none of the 14 psychologists licensed in Guam when this article was written are authorized to prescribe. To our knowledge, this absence of an actual impact of Guam's legislation on patient care in Guam or on psychologists' activities there has never been acknowledged by RxP proponents as they have routinely cited it when advocating for RxP in discussions with their colleagues and legislators.

New Mexico and Louisiana are the only states that have enacted RxP legislation in 2002 and 2004, respectively. As of the writing of this article (i.e., about a decade after passage of enabling legislation), only 26 psychologists were authorized to prescribe in New Mexico (another nine are considered conditional) and only 71 in Louisiana. These numbers represent small percentages of the licensed psychologists by psychology boards in New Mexico (3.7\%; 705) and 
Louisiana $\left(10.7 \%^{1}\right.$ of 665$)$, and a trivial fraction $(0.1 \%)$ of the estimated 92,227 clinically trained psychologists nationally (Substance Abuse and Mental Health Services Administration, 2012). A review of the medical and nursing boards' annual reports of those states reveals that these numbers are also much smaller than the number of advanced practice nurses (APN) and physician assistants (PA) who can prescribe in New Mexico (1,286 APN; 688 PA) and Louisiana (3,939 APN; 712 PA) respectively. The influence of psychologist prescribers in addressing the medication needs in these states relative to other physician and non-physician prescribers would appear minimal based on the numbers alone, further raising questions about the actual impact of promoting RxP.

Prescribing psychologists' impact on the delivery of mental health services in those jurisdictions that authorize it has not been systematically assessed. No large scale, objective evaluations of the impact of psychologists prescribing, or the potential problems associated with it, have been undertaken or published. To the authors' knowledge, none are planned. The bounds of the "mission creep" seeking to broaden psychology's purview to prescribing (Heesacker, 2005) are not known. Some proponents propose that psychologists' formulary should extend beyond psychopharmacology, on which the RxP movement was originally focused, and to which psychopharmacology training is principally dedicated, to other medications such as for weight loss, sleep disorders, chronic pain, and nicotine addiction (Earles, James, \& Folen, 2006).

Despite the expansive vision of RxP proponents, the superficial appeal of their rhetoric, and the disproportionate attention they have garnered within the 
profession, the RxP legislative record has been lackluster. Fox et al. (2009) estimated that at least $88 \mathrm{RxP}$ legislative initiatives had been introduced in 21 jurisdictions. Using a somewhat different methodology that counts specific bills, we estimate that 170 initiatives to authorize psychologist prescribing have been introduced in about half of the U.S. states and two territories. Figure 3 presents a map of RxP initiatives introduced between 1995 and 2012. Of these bills, 167 $(98.2 \%)$ failed. No states have enacted RxP legislation since 2004. Some bills have failed to garner adequate support in legislatures. Two met gubernatorial veto. In 2013, additional bills in New Jersey and Illinois were defeated but are not included in this analysis because they technically may still be introduced in 2013. Although a precise, cumulative tally of the lobbying and other resources APA has marshaled to promote RxP is not available, the paltry record of enactment of RxP legislation reveals that the RxP agenda has been costly for the profession. We believe the record deserves psychologists' close attention. It raises critical questions as to whether in lobbying for the still controversial RxP agenda professional organizations are exercising prudent stewardship of their resources (e.g., dues revenues).

\section{Other Effects of Promoting the RxP Agenda}

Pursuing RxP arguably has diverted the profession's attention and resources from dealing with other matters, such as lobbying for additional funding levels for psychological services, graduate education, scientific research and preparing for medical homes and accountable care organizations (ACOs). It has also distracted from focusing on the development of clinical practice guidelines and 
policies that might better meet the needs of the public and practitioners, and from addressing other pressing professional matters (e.g., workforce, internship imbalance, equity, health reform and healthcare redesign, licensure mobility).

Moreover, psychologists' pursuit of RxP undermines interprofessional relations with disciplines that oppose RxP and is divisive among psychologists. Since just "a small minority of psychologists" has ever been expected to seek prescription privileges (Smyer et al., 1993), APA's and APAPO's allocations of resources to promote RxP have disproportionately served relatively few psychologists, rather than the broader profession. These priorities and the attendant stewardship of resources diminishes support for the APA among psychologists who view the RxP as a misguided agenda and as incompatible with their values, and/or irrelevant to their aspirations, activities and needs.

Over a decade ago, Heiby (2002b) proposed a moratorium on legislation enabling RxP due to the absence of sound outcome data related to the training model and the RxP movement's divisiveness. To the authors' knowledge only one published study has sought to evaluate the impact, utility and safety of prescribing psychologists in practice. Shearer and colleagues (2012) recently surveyed 47 primary care providers and residents who worked closely with a single (i.e., $n=1$ ) prescribing psychologist in a family medicine clinic in an Army medical center. Although they concluded their study provided evidence that prescribing psychologists "practice safely and effectively" (Shearer, Harmon, Seavey, \& Tiu, 2012, p. 428), this conclusion based on essentially anecdotal data seems premature. 
It is unclear to what degree Level-2 (i.e., Collaboration) trained psychologists, or other psychologists, would receive similar positive ratings by providing consultation, but not prescribing, and what additional services they could provide if not prescribing. Additionally, as Shearer et al. note, the clear limitations in their methodology and sample limit their ability to answer questions about psychologist prescribing. For example, they did not ask whether it would have been preferable to have a psychiatrist provide the psychopharmacological consultation (in person or via telehealth) or what concerns they would have about referring ill and complex patients. They did not assess what medical phenomena related to prescribing psychologists might miss. Needed are more comprehensive investigations of prescribing psychologists (e.g., in New Mexioco and Louisiana) outside the structured setting of military facilities that yield reliable and valid data regarding patient outcomes (i.e., safety and effectiveness) and prescribing patterns in independent (i.e., not military) or less structured settings. Additionally, objective, independent data that evaluate error rates in psychologist prescribing and psychologists' detection rates of adverse effects of medications and that move beyond anecdotal impressions are essential to addressing questions of whether and where prescribing psychologists provide quality care. Similarly, assessments of whether RxP meaningfully affects access to psychoactive medications in underserved areas is warranted.

The history of RxP provides an important case study for psychologists' role in promoting or supporting legislation. It clarifies that unlike other APA policies and guidelines, the outcome of legislative initiatives is not determined by the 
preferences of APA, its council, divisions, committees, taskforces, and members, but rather by a much broader group of stakeholders including governmental authorities, public policy groups, other health professionals and social scientists, consumers, as well as dissenting psychologists. In promoting legislation APA should fully consider the risks, benefits and total capital needed to be expended to successfully pursue its legislative priorities such that it wisely manages its resources. The authors recommend that APA's legislative agenda and efforts focus on the goals and professional activities that benefit its overall membership, rather than supporting $\mathrm{RxP}$, which benefit a small, if vocal, group of psychologists.

Psychologists contribute substantively to the public health through the provision of diverse mental health and broader health services, research, and education, and deserve fuller recognition for the importance of their work. The opportunities for psychologists to flourish in the dawning era of team-based health care are before us. Psychologists' success in this new era will be determined by the quality of their services, their outcomes, and their capacity to collaborate effectively. We believe the public and the profession are best served by having psychologists provide those health services for which they are trained rigorously (e.g., assessment, psychotherapy, consultation, supervision, research, etc.). In many cases, psychologists are indeed the most extensively trained among all health and mental health professionals for rendering them. As interprofessional team-based care revolutionizes the delivery of healthcare, refocusing the profession's psychopharmacology agenda to better prepare psychologists to collaborate with prescribers seems likely to be a more prudent, 
impactful, and promising strategy that would be fully in synch with broader healthcare trends than continuing its undistinguished record in the pursuit of RxP. 


\section{References}

Akiskal, H.S. \& Benazzi, F. (2006). Does the FDA proposed list of possible correlates of suicidality associated with antidepressants apply to an adult private practice population? Journal of Affective Disorders, 91, 105-110. doi: 10.1016/j.jad.2006.04.002

Alliant International University. (2012). Clinical psychopharmacology Postdoctoral MS program. Retrieved May 15, 2012 from http://www.alliant.edu/cspp/programs-degrees/clinicalpsychopharmacology/index.php.

American Association of Applied and Preventive Psychology. (1998). Statement in opposition to prescription privileges for psychologists. Retrieved from http://www.narpa.org/prescribe.htm.

American College of Neuropsychopharmacology (2000). DoD prescribing psychologists external analysis, monitoring, and evaluation of program and its final report. American College of Neuropsychopharmacology Bulletin. 6(3). Retrieved from http://www.acnp.org/Docs/BulletinPdfFiles/vol6no3.pdf. American Psychological Association. (1992). Report of the ad hoc task force on psychopharmacology. Washington, DC: Author.

American Psychological Association. (2007). Guidelines and principles for accreditation of programs in professional psychology. Washington, DC: Author. 
American Psychological Association. (2009). Recommended postdoctoral education and training program in psychopharmacology for prescriptive authority. Washington, DC: Author. 2009. Retrieved from http://www.apapracticecentral.org/advocacy/authority/training-authority.pdf. American Psychological Association (2013). Competencies for psychology practice in primary care. Report of the interorganizational work group on competencies for primary care psychology. Retrieved from http://www.apa.org/ed/resources/competencies-practice.pdf American Psychological Association, Center for Workforce Studies (2010). 2008 APA Survey of Psychology Health Service Providers. Washington DC: Author. Retrieved from: http://www.apa.org/workforce/publications/08hsp/telepsychology/index.aspx.

Andrews, M. (2011, March 21). Psychologists seek authority to prescribe psychotropic medications. The Washington Post. Retrieved May 15, 2012

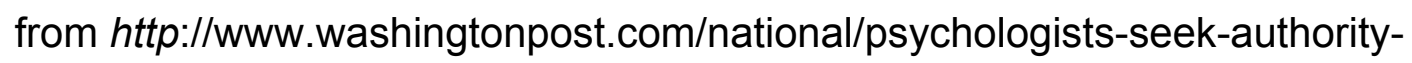
to-prescribe-psychotropic-medications-/2011/03/17/ABosOH8_story.html.

Baird, K. A. (2007). A survey of clinical psychologists in Illinois regarding prescription privileges. Professional Psychology: Research and Practice, 38, 196-202. doi: 10.1037/0735-7028.38.2.196

Bell, P. F., Digman, R. H., \& McKenna, J., P. (1995). Should psychologists obtain prescribing privileges? A survey of family physicians. Professional Psychology: Research and Practice, 26, 371-376. doi: 10.1037/07357028.26.4.371 
Belleville, G. (2010). Mortality hazard associated with anxiolytic and hypnotic drug use in the National Population Health Survey. Canadian Journal of Psychiatry, 55, 558-567. PMID:20840803

Blount, A., Schoenbaum, M., Kathol, R., Rollman, B. L., Thomas, M., O’Donohue, W., \& Peek, C. J. (2007). The economics of behavioral health services in medical settings: A summary of the evidence. Professional Psychology: Research and Practice. 38, 290-297. doi: 10.1037/0735-7028.38.3.290

Bluestein, D. \& Cubic, B. A. (2009). Psychologists and primary care physicians: A training model for creating collaborative relationships. Journal of Clinical Psychology in Medical Settings. 16, 101-112. doi: 10.1007/s10880-009-91569

Budnitz, D. S., Pollock, D. A., Weidenbach, K. N., Mendelsohn, A. B., Schroeder, T. J., \& Annest, J. L. (2006). National surveillance of emergency department visits for outpatient adverse drug events. Journal of the American Medical Association, 296, 1858-1866. doi:10.1001/jama.296.15.1858

Bureau of Labor Statistics (2010). Occupational outlook handbook. Retrieved September 26, 2013 from http://www.bls.gov/ooh/Healthcare/Physicianassistants.htm

Bureau of Labor Statistics (2012). Occupational outlook handbook. Retrieved September 26, 2013 from http://www.bls.gov/oes/current/oes291171.htm Bush, J. W. (2002). Prescribing privileges: Grail for some practitioners, potential calamity for interprofessional collaboration in mental health. Journal of Clinical Psychology, 58, 681-696. doi: 10.1002/jclp.10053 
Butler, M., Kane, R.L., McAlpine, D., Kathol, R. G., Fu, S.S., Hagedorn, H., \& Wilt, T.J. (2008). Integration of mental health/substance abuse and primary care. Evidence Reports/Technology Assessments, No. 173. Rockville, MD: Agency for Healthcare Research and Quality. Retrieved from http://www.ncbi.nlm.nih.gov/books/NBK38632.

California Psychiatric Association (n.d.). Psychologists practicing medicine. Retrieved June 8, 2013 from:

http://www.calpsych.org/legislation/background/historypsycholsandmeds.html Canadian Psychological Association Task Force on Prescriptive Authority for Psychologists in Canada. (2010). Report to the Canadian Psychological Association board of directors. Retrieved from http://www.cpa.ca/docs/file/Task_Forces/CPA_RxPTaskForce_FinalReport_D ec2010_RevJ17.pdf.

Campbell, C. D., Kearns, L. A., \& Patchin, S. (2006). Psychological needs and resources as perceived by rural and urban psychologists. Professional Psychology: Research and Practice, 37, 45-50. doi: 10.1037/07357028.37.1.45

Carlat, D. J. (2010). Unhinged: The trouble with psychiatry - A doctor's revelations about a profession in crisis. New York, New York: Free Press. Center for Mental Health, Department of Health, Mind, NHS Confederation Mental Health Network, Rethink Mental Illness, \& Turning Point. (2012). No health without mental health: Implementation framework. Retrieved from Department of Health website: http://www.dh.gov.uk/health/files/2012/07/No- 
Health-Without-Mental-Health-Implementation-Framework-Report-accessibleversion.pdf

Chomienne, M. H., Grenier, J., Gadboury, I., Hogg, W., Ritchie, P., \& Farmanova-Haynes, E. (2011). Family doctors and psychologists working together: Doctors' and patients' perspectives. Journal of Evaluation in Clinical Practice, 17, 282-287. doi: 10.1111/j.1365-2753.2010.01437.x

Cubic, B., Mance, C., Turgesen, J. N., \& Lamanna, J. D. (2012). Interprofessional education: Preparing psychologists for success in integrated primary care. Journal of Clinical Psychology in Medical Settings, 19, 84-92. doi: 10.1007/s10880-011-9291-y.

Cuijpers, P., Dekker, J., Hollon, S. D. \& Andersson, G. (2009). Adding psychotherapy to pharmacotherapy in the treatment_of depressive_disorders in adults: A meta-analysis. Journal of Clinical Psychiatry, 70, 1219-1229. doi: doi: 10.4088/JCP.09r05021

DeLeon, P. H. (2002). Presidential reflections: Past and future. American Psychologist, 57, 425-430. doi: 10.1037/0003-066X.57.6-7.425

DuBosar, R. (2009, November). Psychotropic drug prescriptions by medical specialty. American College of Physicians Internist. Retrieved from http://www.acpinternist.org/archives/2009/11/national-trends.htm Earles, J. E., James, L. C., \& Folen, R. A. (2006). Prescribing nonpsychopharmacological agents: A new potential role for psychologists in primary care settings and specialty clinics. Journal of Clinical Psychology, 62, 1213-1220. doi: 10.1002/jclp.20304 
Fournier, J. C., DeRubeis, R. J., Hollon, S. D., Dimidjian, S., Amsterdam, J. D., Shelton, R. C., \& Fawcett, J. (2010). Antidepressant drug effects and depression severity: A patient-level meta-analysis. Journal of the American Medical Association. 303, 47-53. doi:10.1001/jama.2009.1943

Fox, R. E., DeLeon, P. H., Newman, R., Sammons, M.T., Dunivin, D. L., \& Baker, D. C. (2009). Prescriptive authority and psychology: A status report. American Psychologist, 64, 257-268. doi: 10.1037/a0015938

Frank, R., Bray, J. H., McDaniel, S. H., \& Heldring, M. (Eds.). (2003). Primary care psychology. Washington, DC: APA.

Gentile, S. (2011). Drug treatment for mood disorders in pregnancy. Current Opinion in Psychiatry, 24, 34-40. doi: 10.1097/YCO.Ob013e3283413451.

Government Accounting Office (GAO) Need For More Prescribing Psychologists Is Not Adequately Justified. Washington, DC: United States General Accounting Office; April, 1997. Retrieved May 15, 2012 from: http://www.gao.gov/archive/1997/he97083.pdf.

Hayes, S. C., \& Heiby, E. M. (Eds.). (1998). Prescription Privileges for Psychologists: A Critical Appraisal. Reno, NV: Context Press.

Hayes, S., C, Walser, R. D., \& Bach, P. (2002). Prescription privileges for psychologists: Constituencies and conflicts. Journal of Clinical Psychology, 58, 697-708. doi: 10.1002/jclp.10054

Health Service Psychology Education Collaborative (2013). Professional psychology in health care services: A blueprint for education and training. American Psychologist, 68, 411-426. doi: 10.1037/a0033265 
Health Resources and Services Administrator (2010, September). Advisory committee on interdisciplinary, community-based linkages $-10^{\text {th }}$ annual report to the secretary of the United States Department of Health and Human Services and the Congress of the United States. Retrieved from http://www.hrsa.gov/advisorycommittees/bhpradvisory/acicbl/Reports/acicbl_t enth_report_final.pdf

Heath, B., Wise, R. P., \& Reynolds K. (2013, March). A standard framework for levels of integrated healthcare. Washington, D.C.SAMHSA-HRSA Center for Integrated Health Solutions.

http://www.integration.samhsa.gov/resource/standard-framework-for-levelsof-integrated-healthcare

Heesacker, M. (2005). Jack of all trades, master of none?: An alternative to clinical psychology's market-driven mission creep. Journal of Clinical Psychology. 61, 1067-1070. doi: 10.1002/jclp.20138

Heiby, E. M. (2002a). Concluding remarks on the debate about prescriptive privileges for psychologists. Journal of Clinical Psychology. 58,709-722. 10.1002/jclp.10055.

Heiby, E. M. (2002b). It is time for a moratorium on legislation enabling prescription privileges for psychologists. Clinical Psychology: Science and Practice, 9, 256-258. doi: 10.1093/clipsy.9.3.256

Heiby, E. M. (2010). Concerns about substandard training for prescription privileges for psychologists. Journal of Clinical Psychology. 66, 104-111. doi: 10.1002/jclp.20650 
Institute of Medicine. (2013). Interprofessional education for collaboration:

Learning how to improve heath from interprofessional models across the continuum of education to practice: Workshop summary. Washington DC: The National Academies Press.

Institute of Medicine, Committee on Crossing the Quality Chasm: Adaptation to Mental Health and Addictive Disorder. (2006). Improving the quality of health care for mental and substance-use conditions: Quality Chasm Series. Washington, DC: National Academy Press.

International Society of Psychiatric-Mental Health Nurses. (November, 2001).

Position statement: Response to clinical psychologists prescribing psychotropic medications. Retrieved May 15, 2012 from:

http://www.ispn-psych.org/docs/11-01 prescriptive-authority.pdf. Interprofessional Education Collaborative Expert Panel. (2011). Core competencies for interprofessional collaborative practice: Report of an expert panel. Washington, DC: Author. Retrieved from http://www.aacn.nche.edu/education-resources/ipecreport.pdf.

Kessler R.C., Demler, O., Frank, R.G., Olfson, M., Pincus, H.A., Walters, E.E., . . . Zaslavsky, A.M. (2005). Prevalence and treatment of mental disorders, 1990 to 2003. New England Journal of Medicine, 352, 2515-2523. doi 10.1056/NEJMsa043266

Kingsbury, S. J. (1987). Cognitive differences between clinical psychologists and psychiatrists. American Psychologist, 42, 152-156. doi: 10.1037/0003066X.42.2.152 
Kingsbury, S.J. (1992). Some effects of prescribing privileges. Professional Psychology: Research and Practice, 23, 3-5. doi: 10.1037/0735-7028.23.1.3

Lavoie, K. L., \& Barone, S. (2006). Prescription privileges for Psychologists: A comprehensive review and critical analysis of current issues and controversies. CNS Drugs, 20, 51-66. doi: 10.2165/00023210-20062001000005

McGrath, R. E. (2010). Prescriptive authority for psychologists. Annual Review of Clinical Psychology, 6, 21-47. doi: 10.1146/annurev-clinpsy-090209151448

Moore, T. J., Cohen, M. R., \& Furberg, C. D. (2007). Serious adverse drug events reported to the Food and Drug Administration, 1998-2005. Archives of Internal Medicine, 167, 1752-1759. doi:10.1001/archinte.167.16.1752

Mundinger, M. O., Kane, R. L., Lenz, E. R., Totten, A.M., Tsai, W., Cleary, P.D., Friedewald, W. T., Siu, A. L., Shelanski, M. L. (2000). Primary care outcomes in patients treated by nurse practitioners or physicians: A randomized trial. Journal of the American Medical Association, 283(1), 59-68. doi:10.1001/jama.283.1.59.

Muse, M. \& McGrath, R. E. (2010). Training comparisons among three professions prescribing psychoactive medications: Psychiatric nurse practitioners, physicians, and pharmacologically trained psychologists. Journal of Clinical Psychology, 66(1), 96-103. doi:10.1002/jclp.20623 
New Mexico State University (2011). Master's program in clinical psychopharmacology course outline. Retrieved May 15, 2012 from http://education.nmsu.edu/cep/siap/documents/cep-804.pdf.

Pardes, H. \& Pincus, H. A. (1983). Report of the Graduate Medical Education National Advisory Committee and health manpower development. Archives of General Psychiatry, 40, 97-102.

O’Reilly, R., Bishop, J., Maddox, K., Hutchinson, L., Fisman, M., \& Takhar J. (2007). Is telepsychiatry equivalent to face-to-face psychiatry? Results from a randomized controlled equivalence trial. Psychiatric Services, 58, 836-843. doi: 10.1176/appi.ps.58.6.836

Pollitt, B. (2003). Fool's gold: Psychologists using disingenuous reasoning to mislead legislatures into granting psychologists prescriptive authority. American and Journal of Law \& Medicine. 29, 489-514.

Robiner, W. N. (2006). The mental health professions: Workforce issues and challenges. Clinical Psychology Review, 26(5), 600-625. doi:10.1016/j.cpr.2006.05.002

Robiner, W. N., Bearman, D. L., Berman, M., Grove, W. M., Colón, E., Armstrong, J., \& Mareck, S. (2002). Prescriptive authority for psychologists: A looming health hazard? Clinical Psychology: Science and Practice, 9, 231-248. doi: 10.1093/clipsy.9.3.231

Robiner, W. N., Bearman, D. L., Berman, M., Grove, W. M., Colón, E., Armstrong, J., Mareck, S., Tanenbaum, R. (2003). Prescriptive authority for psychologists: Despite deficits in education and knowledge? Journal of 
Clinical Psychology in Medical Settings, 10, 211-222. doi: 1068$9583 / 03 / 0900-0211 / 0$

Shearer, D. S., Harmon, S. C., Seavey, B. M., \& Tiu, A. Y. (2012). The primary care prescribing psychologists model: Medical provider ratings of the safety, impact and utility of prescribing psychology in a primary care setting. Journal of Clinical Psychology in Medical Settings, 19, 420-429.

Smyer, M. A., Balster, R. L., Egli, D., Johnson, D. L., Kilbey, M. M., Leith, N. J., \& Puente, A.E. Summary of the Report of the Ad Hoc Task Force on Psychopharmacology of the American Psychological Association. (1993). Professional Psychology: Research and Practice, 24, 394-403. doi: $10.1037 / 0735-7028.24 .4 .394$

Snowden L. R. \& Pingitore, D. (2002). Frequency and scope of mental health service delivery to African Americans in primary care. Mental Health Services Research, 4, 123-130.

Society for a Science of Clinical Psychology. (July 2001). Task Force Statement on Prescription Privileges for Psychologists. Retrieved May 15, 2012 from: http://www.mspp.net/SSCPscriptpriv.htm.

Spielmans, G. I., Thiegles, S. A., Dent, A. L., Greenberg, R. P. (2008). The accuracy of psychiatric medication advertisements in medical journals. Journal of Nervous and Mental Disease. 196, 267-273. doi:

10.1097/NMD.0b013e31816a436b 
Stambor, Z. (2006, July). Psychology's prescribing pioneers. Medical and prescribing psychologists in Louisiana and New Mexico claim added patient benefits. Monitor on Psychology, 37 (7), 30.

Stuart, R. B. \& Heiby, E. M. (2007). To prescribe or not to prescribe: Eleven exploratory questions. Scientific Review of Mental Health Practices, 5, 4-32.

Substance Abuse and Mental Health Services Administration. (2012). Mental Health, United States, 2010. HHS Publication No. (SMA) 12-4681. Rockville, MD: Substance Abuse and Mental Health Services Administration.

Tatman, S. M., Peters, D. B., Greene, A. L., \& Bongar, B. (1997). Graduate students' attitudes toward prescription privileges training. Professional Psychology: Research and Practice. 28, 50-517. doi: 10.1037/07357028.28.6.515

Tovian, S. (2006). Interdisciplinary collaboration in outpatient practice. Professional Psychology: Research and Practice, 37, 268-272.

Vega W. A., Kolody B., Aguilar-Gaxiola S., \& Catalano R. (1999). Gaps in service utilization by Mexican Americans with mental health problems. American Journal of Psychiatry, 156(6), 928-934.

Wagner, M.K. (2002). The high cost of prescription privileges. Journal of Clinical Psychology, 58, 677-680. doi: 10.1002/jclp.10052

Walters, G.D. (2001). A meta-analysis of opinion data on the prescription privilege debate. Canadian Psychology, 42, 119-125. doi: 10.1037/h0086886 Wang P.S., Aguilar-Gaxiola, S., Alonso J., Angermeyer M.C., Borges, G., Bromet, E.J., . . Wells, J.E. (2007). Use of mental health services for anxiety, mood, 
and substance disorders in 17 countries in the WHO world mental health surveys. Lancet, 370, 841-850. doi 10.1016/S0140-6736(07)61414-7.

Wang P.S., Demler, O., \& Kessler, R.C. (2002). Adequacy of treatment for serious mental illness in the United States. American Journal of Public Health, 92, 92-98.

Wang P.S., Lane, M., Olfson, M., Pincus, H.A., Wells, K. B., \& Kessler, R. C. (2005). Twelve-month use of mental health services in the United States: Results from the National Comorbidity Survey Replication. Archives of General Psychiatry, 62, 629-40. doi 10.1001/archpsyc.62.6.629

Westra, H. A., Eastwood, J. D., Bouffard, B. B., \& Gerritsen, C. J. (2006).

Psychologist's pursuit of prescriptive authority: Would it meet the goals of Canadian health care reform? Canadian Psychology, 47, 77-95. doi: 10.1037/cp2006001

Whitaker, R. (2010). Anatomy of an epidemic: Magic bullets, psychiatric drugs and the astonishing rise of mental illness in America. New York, New York: Crown Publishers.

World Health Organization (WHO). (2010). Framework for action on interprofessional education and collaborative practice. Retrieved from http://whqlibdoc.who.int/hq/2010/WHO_HRH_HPN_10.3_eng.pdf

Xierali, I. M., Tong, S. T., Petterson, S. M., Puffer, J. C., Phillips, R. L., \& Bazemore, A. W. (2013). Family physicians are essential for mental health care delivery. Journal of the American Board of Family Medicine, 2, 114-115. doi 10.3122/jabfm.2013.02.120219 


\section{Footnotes}

${ }^{1}$ Because prescribing psychologists in Louisiana are now licensed by the Louisiana State Board of Medical Examiners (LSBME) but still have the option of being duly licensed by the Louisiana State Board of Examiners of Psychologists (LSBEP) as well, we could not determine what the total number of psychologists is in the state. Hence, the figure cited, 665, is based on the LSBEP number data and may not include all of the psychologists. As such, the $10.7 \%$ estimate percentage of all Louisiana psychologists who can prescribe, is probably an overestimate of the actual proportion of prescribing psychologists. Unfortunately, the LSBEP does not track the number of psychologists licensed with both boards. 
Table 1

Knowledge base and clinical proficiencies required for prescribing

Psychopathology and

Psychological Issues
Medical Status Prior to

Prescribing
Response to Treatments

Comorbid medical conditions

Contraindications conditions

Prevalence and course of psychiatric conditions

Knowledge of Nonpharmacologic treatment options
Medical effects of concurrent treatments

1. Drug interactions

2. Other treatments (e.g., dialysis, plasmapheresis)

Long-term effects of medications
Knowledge of adverse reactions

1. Side effects

2. Toxic effects

Ability to recognize, diagnose, and treat adverse reactions

Ability to differentiate between physical and psychiatric effects of psychoactive agents and concurrent medications

Other issues related to monitoring titrating, or discontinuing prescribed medications

History of medication use

Note. The education of psychologists typically addresses column 1, but neglects columns 2 and 3. Based on Robiner et al. (2002). Request to reprint this table would be requested of Clinical Psychology: Science and Practice. 
Figure 1

College Basic Science Prerequisite Courses for Admission to Health Science Programs

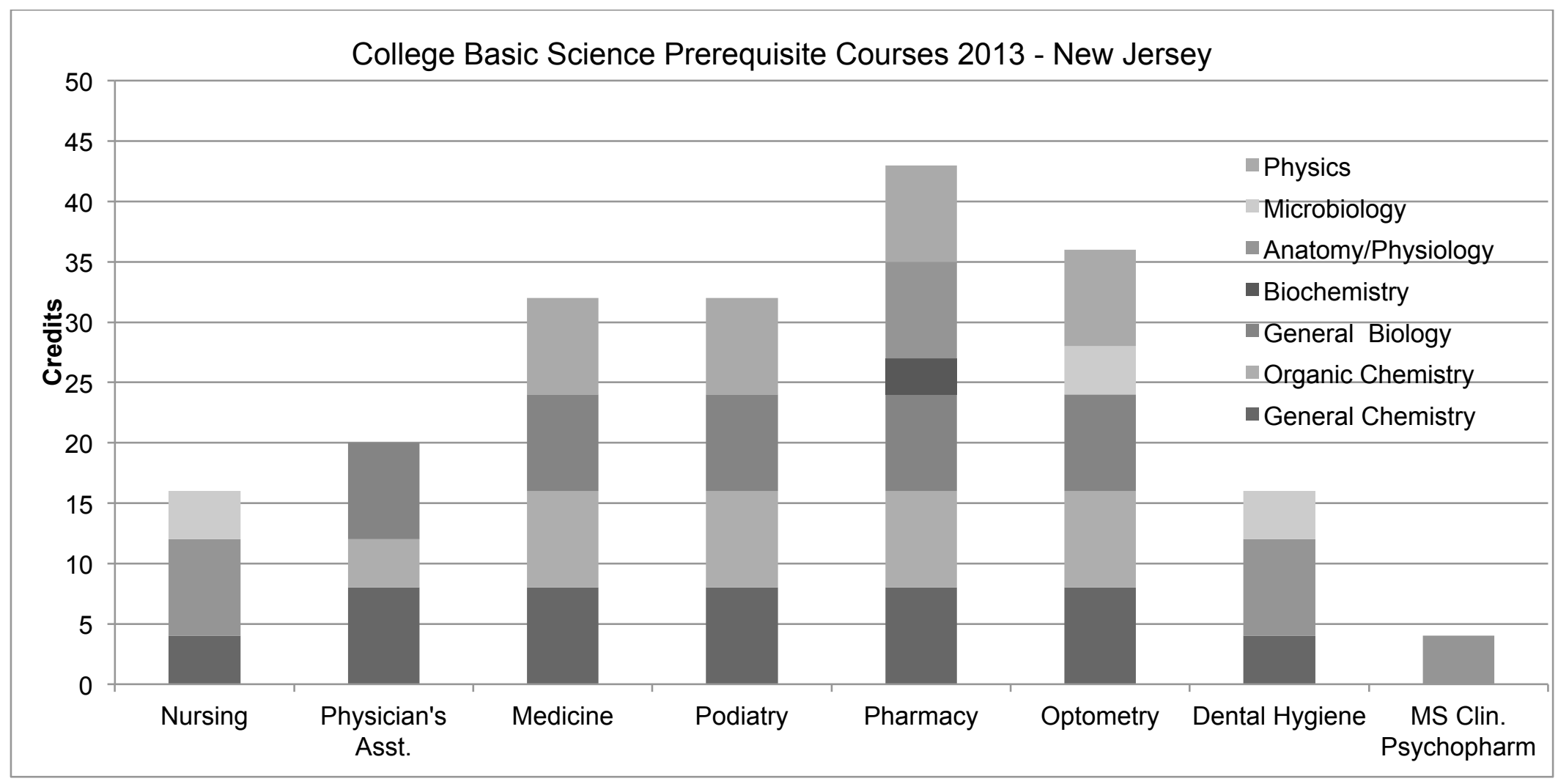

Note. Multiply credits by 10 for estimated hours of instruction. These data were derived by 2013 survey of admission requirements to the largest programs in New Jersey (e.g., Farleigh Dickinson University, University of Medicine and Dentistry of New Jersey, Rutgers University). Although there were no physical or health sciences prerequisites for entry into the Ph.D. programs in Clinical Psychology, both the FDU and Rutgers curriculum included one course in biopsychology or behavioral neuroscience. The MS Clinical psychopharmacology program is an example of a program intended to train psychologists to prescribe, and requires considerably less than programs for other prescribers and non-prescribers. 


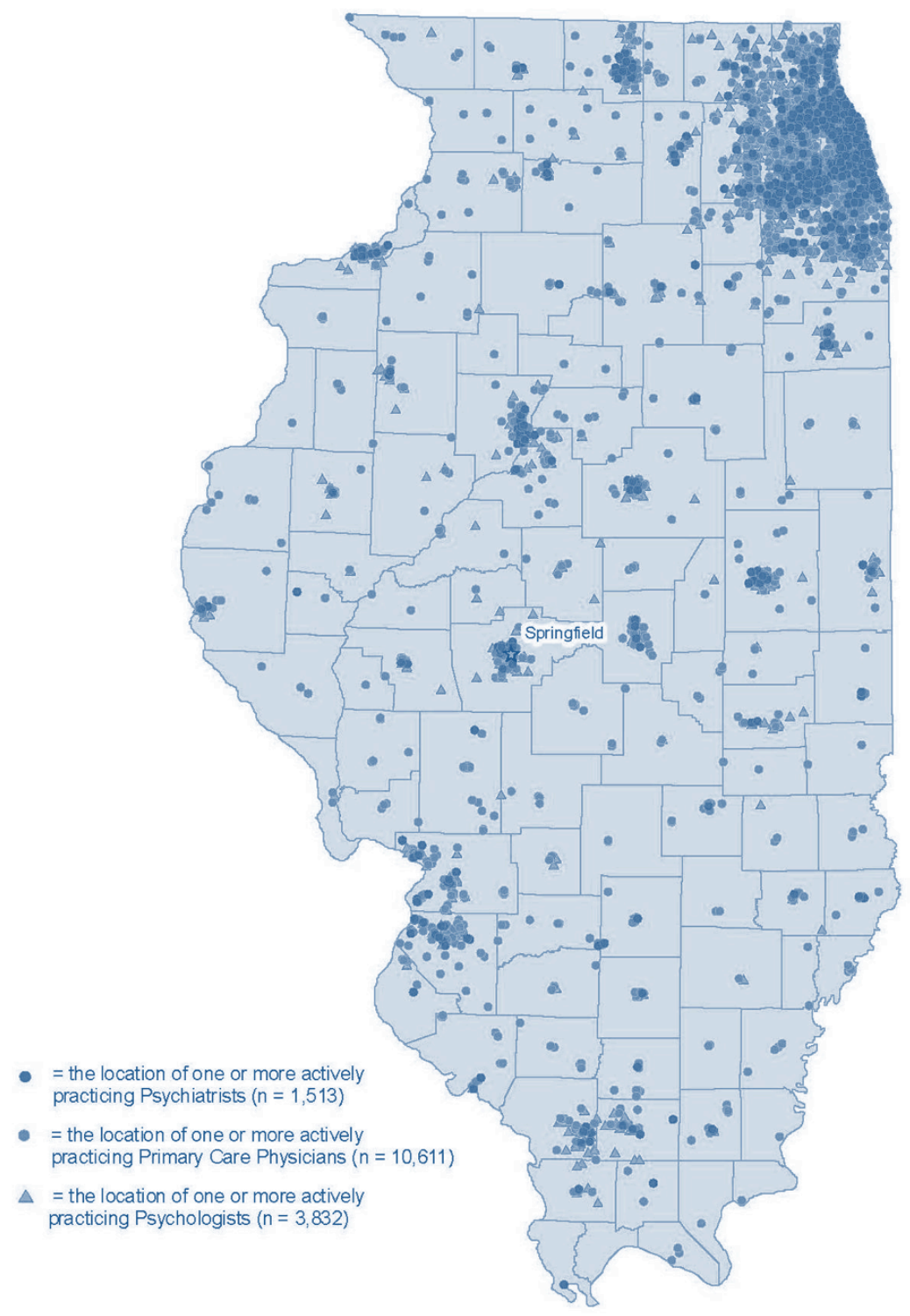

Data Source: American Medical Association, American Osteopathic Association (2008) and the Illinois Dept. of Financial and

Professional Regulation (June 2008)

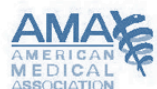

National Center for the Analysis of Healthcare Data (2008)

Figure 2. These data show the geographic distribution comparison for psychiatrists, primary car physicians (PCPs), and psychologists in Illinois. Data are provided for Illinois given that this sta garnered the most attention and resources from the APA during the 2013 legislative session. Arguments for improving rural access were advanced by proponents but the data suggest simili practice locations with more PCP in outlying rural areas. Other states present similar geograph distributions. 


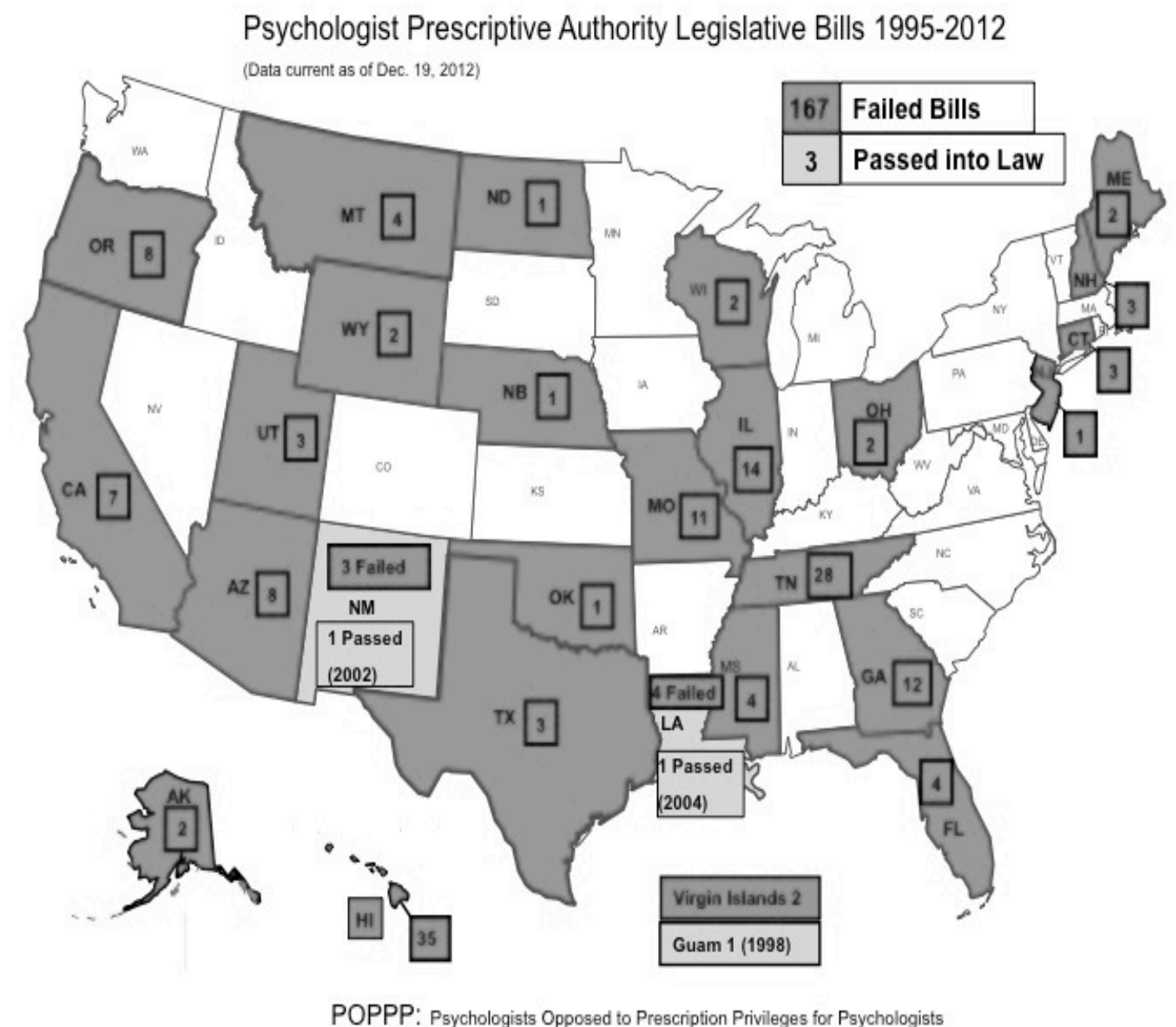

Figure 3. Psychologist prescriptive authority legislative bills from 1995 through 2012 